\title{
Demonstrating Thermal Propagation Test for Battery Pack for PHEV with Laser Irradiation as Initiation Method
}

\author{
Kenichiroh Koshika ${ }^{1)}$ Yuta Kagei $^{2)}$ Hideki Tsuruga $^{3)}$ Keizoh Honda $^{3)}$ \\ 1) National Traffic Safety and Environment Laboratory \\ 42-27 Jindaiji-higashimach 7-chome, Chofu, Tokyo, 182-0012, Japan (E-mail: koshika@ntsel.go.jp) \\ 2) Honda Motor Co., Ltd. \\ 3)Japan Electrical Safety \& Environment Technology Laboratory
}

Received on 10, 15, 2021

\begin{abstract}
The use of laser irradiation for heating is characterized by localized heating and high power density heating, which make the method suitable for conducting thermal propagation tests for battery packs for electrified vehicles. This paper demonstrates a thermal propagation test for battery packs for PHEVs using laser irradiation. It describes one example of the practicality of using laser irradiation as an initiation method for thermal propagation tests for large battery packs for electrified vehicles. One of the advantages of laser irradiation, which is that thermal runaway occurs with minimal heating of adjacent cells, was confirmed to be maintained for the pack level test.
\end{abstract}

KEY WORDS: EV and HV systems, Lithium ion battery, Electrical safety (A3)

\section{Introduction}

Thermal propagation tests have attracted much attention because of safety concerns when increasing the size and energy density of battery packs in vehicles. Various initiation methods for thermal propagation tests, such as heating with an electric heater (thermal approach), nail penetration (mechanical approach), and overcharging (electrical approach), have been widely studied and developed. ${ }^{(1-3)}$ These various methods allow test engineers to choose an appropriate initiation method based on the purpose of the test and the assumed scenario.

Laser irradiation for heating has also been studied and developed as a method for initiating thermal propagation tests. ${ }^{(4,5)}$ Laser irradiation is known to cause thermal runaway rapidly, which is one of its advantages, and so has been used for testing stationary batteries. Indeed, laser irradiation is already included as an initiation method in the heating category in IEC62619 ${ }^{(5)}$.

Laser irradiation for heating is expected to be suitable for thermal propagation in the following scenario, which assumes two phenomena:

(i) Thermal propagation is caused by thermal runaway of a single cell, not two or more.

(ii) The single-cell thermal runaway is caused by local damage of the separator (in the cell).

Assumption (i) ideally requires causing thermal runaway in an initiation cell without heating adjacent cells. In other words, most of the energy that is input by heating should act to cause thermal runaway of the initiation cell, and not increase the temperature of adjacent cells. In practice, however, any initiation method that is categorized in the thermal approach will increase the temperature of adjacent cells. On the other hand, the degree of increase in temperature of adjacent cells depends on the heating characteristics of the method. Laser irradiation is expected to cause thermal runaway with minimal heating of adjacent cells because the thermal runaway rapidly occurs before the heat transferred from the initiation cell greatly increases the temperature of the adjacent cells. Causing thermal runaway in a short time is a reasonable strategy to avoid increasing the temperature of adjacent cells.

Various thermal propagation tests for battery packs in vehicles have been reported. ${ }^{(6,7)}$ However, the initiation methods used in those reports were not laser irradiation but nail penetration and heating by a ceramic heater. To the best of the authors' knowledge, laser irradiation has never been used for heating for thermal propagation tests for battery packs in vehicles. There are two main possible reasons for this. Using laser irradiation as an initiation method is a relatively new idea compared with nail penetration and heating by a ceramic heater, especially for vehicles. Furthermore, there was no laser testing facility or laboratory dealing with battery packs in vehicles in Japan until 2018.

The purpose of this study was to develop a thermal propagation test for evaluating the safety of electrified vehicles. We previously reported on a possible mechanism of thermal runaway caused by laser irradiation and its features. ${ }^{(4)}$ In this paper, we demonstrate a thermal propagation test for a battery pack in a PHEV using laser irradiation for heating as an initiation method. We also confirm the suitability of laser irradiation in the scenario. We also review the heating characteristics of laser irradiation and estimate the mechanism of thermal runaway based on our previous report ${ }^{(4)}$, then describe the demonstration test.

\section{Estimated internal short circuit process of laser irradiation and its heating characteristics ${ }^{(4)}$}

\subsection{Estimated process of thermal runaway caused by laser}

The process of thermal runaway is described for the periods before and after an internal short circuit occurs. Laser irradiation was estimated to cause an internal short circuit by the following 


\section{Kenichiroh Koshika et al. / International Journal of Automotive Engineering}

Vol.13, No.1(2022)

four steps: 1) The temperature of the irradiated area and the area directly below it was increased by laser irradiation. 2) A keyhole ${ }^{(8)}$ (cone-shaped hole) of less than $1 \mathrm{~mm}$ in diameter was formed by laser irradiation. 3) The irradiated part and its peripheral part were heated. The separator, which was heated to more than $160^{\circ} \mathrm{C}$, shrank horizontally, causing a short circuit due to direct contact of the cathode material and anode material. 4) Continued laser irradiation produced a molten pool ${ }^{(9)}$. The molten pool contributed to stable heating of these areas, expanding the short circuit area. Fig. 1 (a) shows that separator shrinkage in the immediate vicinity of the hole caused direct contact of the cathode and anode. A voltage drop of $30 \mathrm{mV}$ was observed in this condition. Fig. 1 (b) shows the generation of the molten pool and the expanded area of the internal short circuit.

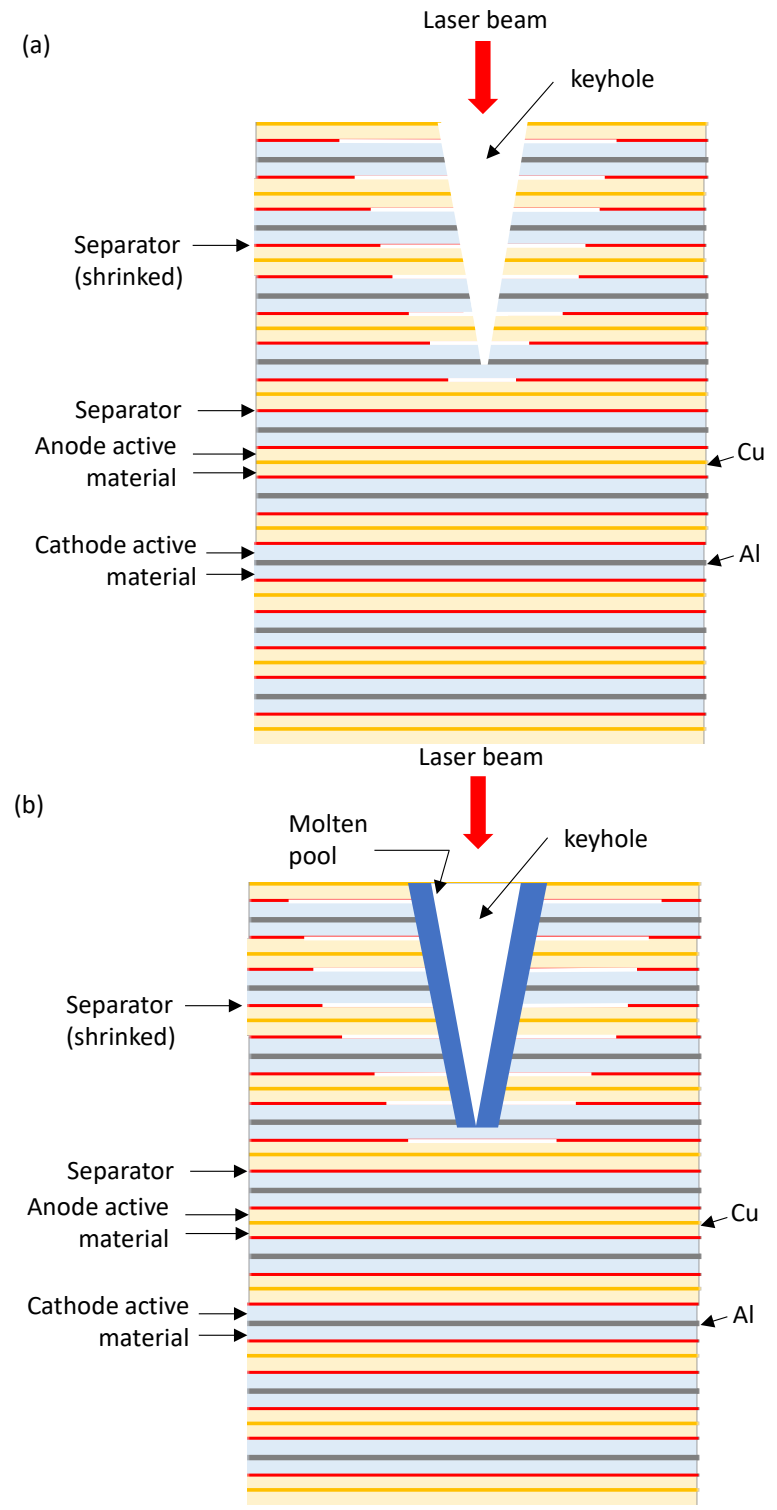

Fig. 1 Schematic image of (a) separator shrinkage in immediate vicinity of the keyhole, causing direct contact between the cathode and anode, and (b) generation of molten pool and extended area of internal short circuit.
Regarding the process of thermal runaway after the internal short circuit, it was considered that the temperature inside the cell continuously increased to the temperature at which thermal runaway occurs due to heating by laser irradiation, Joule heat by the internal short circuit current, and exothermic reactions. Of course, whether thermal runaway occurs depends on the balance between heat input and output in general; this also applies to other heating methods.

\subsection{Heating characteristics of laser irradiation}

The remarkable properties of laser irradiation as a heating initiation method were considered to be localized heating and high power density heating; a laser beam is focused on a initiation cell with high power density. A laser oscillator with a maximum power of $2000 \mathrm{~W}$ was used in this study. With this laser system, we can irradiate a laser beam of more than $7000 \mathrm{~W} / \mathrm{mm} 2$ on the initiation cell. The features were described in our previous report.

The experimental results of using laser irradiation to cause thermal runaway on a lithium iron phosphate (LFP) cathode, 18650 type lithium-ion battery (O'CELL NEW Energy Technology Co., Ltd), are summarized in Table 1 and compared with those of a ceramic heater to highlight the differences semi-quantitatively ("semi" because the comparison was not conducted under optimum conditions). The ceramic heater was selected as a partial heater which can cause thermal runaway for the LFP cathode, 18650 type lithium-ion battery. The area heated by laser irradiation is two orders of magnitude smaller than that by a ceramic heater, and so is "localized heating". The power per unit area of laser irradiation is also two orders of magnitude higher than that of a ceramic heater, and so is "high power density heating". These two characteristics enabled laser irradiation to increase the temperature at which thermal runaway occurs in a shorter time of $120 \mathrm{~s}$ and with a smaller energy input of $6.9 \mathrm{~kJ}$. These features of localized heating and high power density were expected to allow laser irradiation to cause thermal runaway of the initiation cell while suppressing the increase in temperature of adjacent cells in the thermal propagation test.

Table 1. Specific data comparing laser irradiation and a ceramic heater for causing thermal runaway on an LFP cathode, 18650 type lithium-ion battery

\begin{tabular}{|l|c|c|}
\hline Heating method & Laser irradiation & Ceramic heater \\
\hline $\begin{array}{l}\text { Heating area } \\
\left(\mathrm{mm}^{2}\right)\end{array}$ & 0.8 & 212 \\
\hline $\begin{array}{l}\text { Power per unit } \\
\text { area }(\mathrm{W} \mathrm{mm})^{-2}\end{array}$ & 72 & 0.19 \\
\hline Heating time (s) & 120 & 600 \\
\hline Input energy (kJ) & 6.9 & 30 \\
\hline
\end{tabular}




\section{Kenichiroh Koshika et al. / International Journal of Automotive Engineering}

Vol.13, No.1(2022)

\section{Demonstration of a thermal propagation test for a battery pack in electrified vehicles}

\subsection{Research overview}

This section describes the scope of the demonstration experiments and two unique criteria we set. First, we aimed to demonstrate a thermal propagation test for PHEVs at the pack level using laser irradiation for heating, and to confirm that the advantages of laser irradiation remain valid for the pack level test. In this paper, we focus on the results at the module level and pack level. We sequentially conducted experiments at the cell level, module level and pack level. The conditions of laser irradiation were carefully adjusted at the cell level experiments to cause sufficient thermal runaway. This section also explains the two kinds of criteria we set: a criterion for successful target cell initiation and a criterion for pass/fail of the thermal propagation test. The criteria were set based on GTR-20 ${ }^{(10)}$.

\subsection{Methods}

3.2.1. Specifications of the test battery pack

The test battery pack consisted of 14 modules of 12 cells each. The total energy of the pack was $17 \mathrm{kWh}$. The battery pack was designed for PHEVs. Each cell consisted of a lithium nickel cobalt manganese oxide (NCM) cathode, graphite anode and prismatic type aluminum case.

\subsubsection{Selection of location of initiation cell}

The location of the initiation cell was selected as follows:

- The initiation module shall be directly irradiated by laser.

- The initiation module shall have at least one adjacent module.

- The initiation cell shall have adjacent cells.

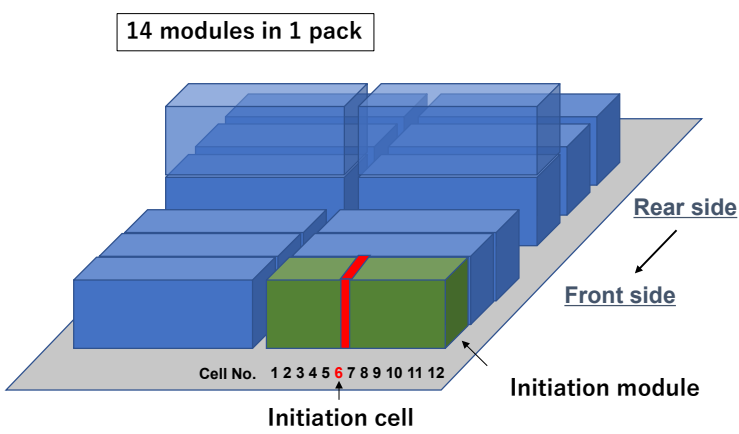

Fig. 2 Schematic image of the location of the initiation cell in the pack

\subsubsection{Layout of laser irradiation}

The distance between the laser processing head and the initiation cell was $50 \mathrm{~cm}$. The laser was irradiated at 8 degrees from the horizontal to avoid the reflected laser damaging the laser processing head (Fig. 3).

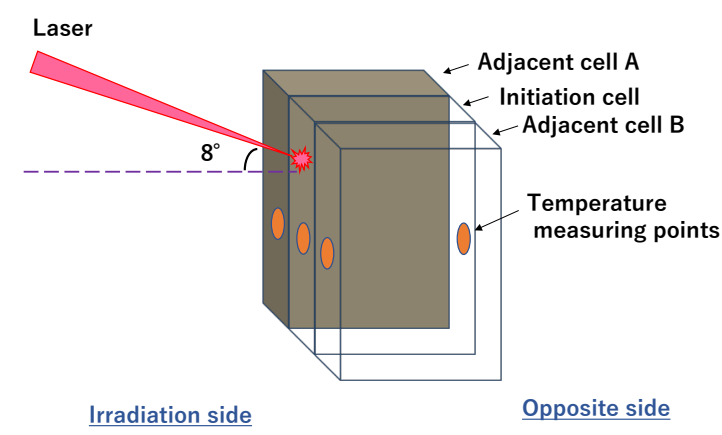

Fig. 3 Schematic image of layout of laser irradiation and temperature measurement points

\subsubsection{Heating by laser irradiation}

The laser irradiation is performed by a continuous wave disk laser with a maximum output of $2000 \mathrm{~W}$. The averaged laser power is $143 \mathrm{~W}$ for irradiation.

3.2.5. Temperature measurement for initiation cell and adjacent cells

The temperature of the initiation cell was measured by thermocouples on the laser irradiation side and on the opposite side (Fig. 3). It was considered that the laser irradiation side had a greater effect on temperature increase compared with the opposite side, and so the temperature of the opposite side was monitored for judging the success criterion. On the other hand, the laser irradiation side of adjacent cells was measured as the temperature of adjacent cells, in order to monitor the suppression of temperature increase of adjacent cells, because the laser irradiation side was expected to have a greater effect on temperature increase compared with the opposite side.

3.3. Setting the success criterion for target cell initiation and pass/fail criterion for the thermal propagation test

The success criterion and the pass/fail criterion were set respectively before conducting the test. The thermal propagation test was divided into two phases: the initiation phase and the propagation phase. The thermal propagation test in this study was designed on the assumption that thermal runaway would occur in a single cell. Therefore, the success criterion for target cell initiation must be set to confirm that single-cell thermal runaway occurs sufficiently. On the other hand, the thermal propagation test should be conducted to ensure that the tested vehicle meets the thermal propagation requirements. One of these requirements is given in GTR-20 as: "The vehicle shall provide an advance warning indication to allow egress or 5 minutes prior to the presence of a hazardous situation inside the passenger compartment caused by thermal propagation which is triggered by an internal short circuit leading to a single cell thermal runaway such as fire, explosion or smoke."

3.3.1. Setting the success criterion for target cell initiation

The success criterion for target cell initiation in this case was set as follows based on the cell level experiments for adjusting the irradiation conditions. 
Vol.13, No.1(2022)

Table 2: Success criterion for target cell initiation compared with "detection of thermal runaway" described in GTR-20

\begin{tabular}{|l|l|}
\hline $\begin{array}{l}\text { GTR-20 } \\
\text { Detection of thermal runaway }\end{array}$ & $\begin{array}{l}\text { This paper } \\
\text { Success criterion for target } \\
\text { cell initiation }\end{array}$ \\
\hline $\begin{array}{l}\text { (i) The measured voltage of } \\
\text { the initiation cell drops }\end{array}$ & $\begin{array}{l}\text { (i) The measured voltage of } \\
\text { the initiation cell drops } \\
\text { below } 2.0 \mathrm{~V}\end{array}$ \\
\hline $\begin{array}{l}\text { (ii) The measured temperature } \\
\text { exceeds [the maximum } \\
\text { operating temperature defined } \\
\text { by the manufacturer] }\end{array}$ & $\begin{array}{l}\text { (ii) The measured } \\
\text { temperature exceeds } 200^{\circ} \mathrm{C}\end{array}$ \\
\hline $\begin{array}{l}\text { (iii) dT/dt } \geq\left[1^{\circ} \mathrm{C} / \mathrm{s}\right] \text { of the } \\
\text { measured temperature }\end{array}$ & $\begin{array}{l}\text { (iii) dT/dt } \geq 10^{\circ} \mathrm{C} / \mathrm{s} \text { of the } \\
\text { measured temperature }\end{array}$ \\
\hline $\begin{array}{l}\text { Thermal runaway can be } \\
\text { judged when: } \\
\text { (a) Both (i) and (iii) are } \\
\text { detected; or } \\
\text { (b) Both (ii) and (iii) are } \\
\text { detected. }\end{array}$ & $\begin{array}{l}\text { Successful initiation can be } \\
\text { judged when: } \\
\text { All of (i), (ii) and (iii) are } \\
\text { detected }\end{array}$ \\
\hline
\end{tabular}

The success criterion for target cell initiation fully covered "Detection of thermal runaway" described in GTR-20. Thus, using laser irradiation for initiation provided sufficient voltage drop, maximum temperature and dT/dt. Therefore, the pass/fail criterion must be newly set for this pack level test without a passenger compartment.

3.3.2. Setting the pass/fail criterion for the pack level test without the passenger compartment

We newly set the pass/fail criterion for this pack level test as follows. "No fire or explosion, and no smoke originating from adjacent cells outside of the plastic covering the battery pack within 5 minutes after a thermal event." This criterion is considered to be harsher than the thermal propagation requirements because even if there is an external fire or explosion and smoke is observed on the outside of the plastic covering the battery pack, it may not enter the passenger compartment.

\subsection{Results}

\subsubsection{Test for modules}

A thermal propagation test of a battery module with a top cover was conducted. A cell located in the middle of the module was selected as the initiation cell. The open circuit voltages (OCVs) and temperatures of the cells (not only the initiation cell and but also adjacent cells) were monitored (Fig. 4). The occurrence of thermal events for the cells, such as explosion, fire, smoke and venting, were also monitored. The advantage of laser irradiation was confirmed to be maintained based on the monitored temperatures of the adjacent cells.

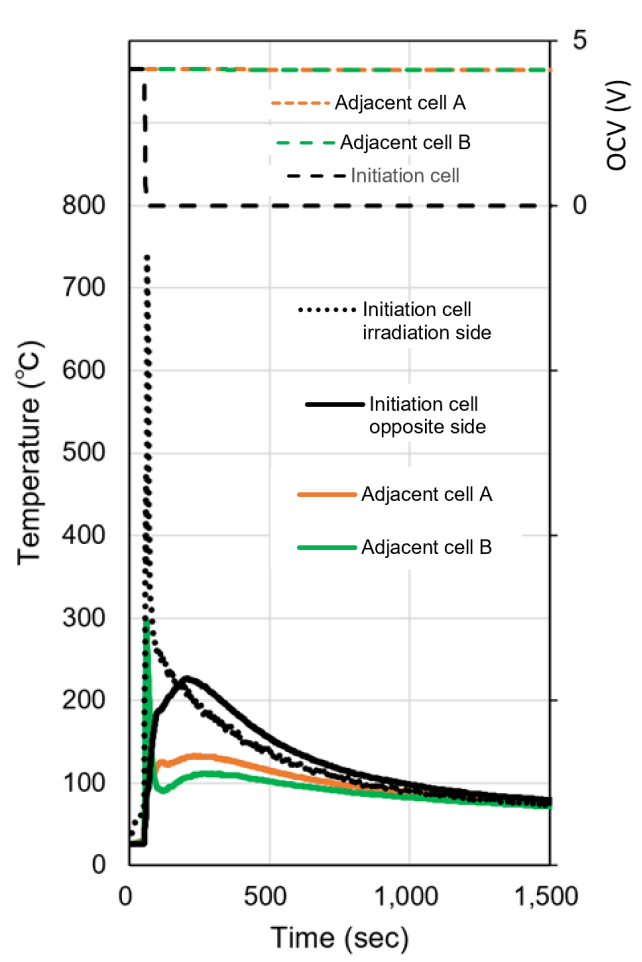

Fig. 4 Temperature and OCV profile for module test

(i) Thermal event observed outside of the battery module with a top cover

Venting was observed at $52 \mathrm{~s}$ after the start of irradiation. White smoke of the venting gas covered the module because the top cover blocked vertical venting. The vaporized electrolyte in the gas flared up at $53 \mathrm{~s}$ after being ignited by some ignition source, which may have been laser-induced spatter. The flames caused by the vaporized electrolyte covered the battery module. Violent flames subsided at $70 \mathrm{~s}$. It is considered that the violent flames between 53 and $70 \mathrm{~s}$ affected the temperature data (between 53 and 100) sampled by the thermocouples on the laser irradiation side.

(ii) Initiation cell

The OCV of the initiation cell started to decrease at $49 \mathrm{~s}$ after the start of irradiation. The safety system operated for gas venting at $52 \mathrm{~s}$. Laser irradiation was stopped at $56 \mathrm{~s}$. The $\mathrm{OCV}$ of $0.0 \mathrm{~V}$ was monitored at $64 \mathrm{~s}$. The temperature reached a high of $227^{\circ} \mathrm{C}$, then gradually decreased. The highest average temperature elevation rate $(\mathrm{dT} / \mathrm{dt})$ was $12^{\circ} \mathrm{C} / \mathrm{s}$ at $60 \mathrm{~s}$. The initiation was judged to be successful.

(iii) Adjacent cells

The OCVs of the adjacent cells were maintained at $4.1 \mathrm{~V}$ until the end. The safety system for venting was not operated until the end. The temperatures reached highs of $132^{\circ} \mathrm{C}$ and $111^{\circ} \mathrm{C}$ (excluding the period of $53-100 \mathrm{~s}$ ), then gradually decreased. The temperature deference of c.a. $20^{\circ} \mathrm{C}$ between adjacent cell $\mathrm{A}$ and $\mathrm{B}$ was generally estimated to be occurred by influence of module structure and/or influence of temperature measuring system including thermocouple contact condition. Thermal events were not observed on adjacent cells. 


\section{Kenichiroh Koshika et al. / International Journal of Automotive Engineering}

Vol.13, No.1(2022)

(iv) Thermal event propagation

Venting from the initiation cell occurred, then smoke and fire from the initiation cell were observed. An explosion from the initiation cell was not observed. On the other hand, venting from adjacent cells did not occur. Therefore, it was confirmed that thermal events on the initiation cell, such as explosion, fire, smoke and venting, did not propagate to the adjacent cells.

(v) Confirmation of maintaining the advantage

One of the advantages of causing thermal runaway with minimal heating of adjacent cells was shown to be maintained in the module level test because the temperature increase of adjacent cells was so small (Fig. 4). The rapid increase in temperature of the initiation cell (irradiation side) after $50 \mathrm{~s}$ was caused by the addition of internal heat from the cell to the external heat from the laser. Therefore, the time frame of $0-50 \mathrm{~s}$ was selected to focus on the external heat from the laser, excluding internal heat from the cell. The temperature of the initiation cell (irradiation side) increased from $26^{\circ} \mathrm{C}$ to $61^{\circ} \mathrm{C}$, that of adjacent cell $\mathrm{A}$ increased from $26^{\circ} \mathrm{C}$ to $28^{\circ} \mathrm{C}$, and that of adjacent cell $\mathrm{B}$ increased from $26^{\circ} \mathrm{C}$ to $29^{\circ} \mathrm{C}$. Thus, the temperature increase of adjacent cells was lower than that of the initiation cell.

\subsubsection{Test for packs}

A thermal propagation test of a battery pack was conducted. A module located in the front left of the pack was selected as the initiation module. The occurrence of thermal events such as explosion, fire, smoke and venting was monitored. The OCVs and temperatures of the cells were also monitored (Fig. 5). The data of OCVs were sampled only until around $300 \mathrm{~s}$ because of a trouble with the recording device. Pass/fail of the test was judged based on the criterion. Based on the monitoring temperature of adjacent cells, it was confirmed that the advantage of laser irradiation was maintained.

(i) Thermal event observed outside of the plastic covering the battery pack

Venting gas was observed at $215 \mathrm{~s}$. The gas caught fire at $216 \mathrm{~s}$ because the vaporized electrolyte was ignited by some ignition source, which may have been laser-induced spatter. The fire went out at $222 \mathrm{~s}$. The smoke disappeared at $300 \mathrm{~s}$.

(ii) Initiation cell

The OCV of the initiation cell started to decrease at $214 \mathrm{~s}$ after the start of irradiation. Laser irradiation was stopped at 219 $\mathrm{s}$. The OCV of $0.0 \mathrm{~V}$ was monitored at $230 \mathrm{~s}$. The temperature reached a high of $254^{\circ} \mathrm{C}$, then gradually decreased. The highest temperature elevation rate $(\mathrm{dT} / \mathrm{dt})$ was $27^{\circ} \mathrm{C} / \mathrm{s}$ at $219 \mathrm{~s}$. The initiation was judged to be successful. After opening the plastic cover, venting from the initiation cell was confirmed.

(iii) Adjacent cells

The OCVs of the adjacent cells were maintained at $4.1 \mathrm{~V}$ until the end, indicating no occurrence of internal short circuit. (After the experiment, the voltages of adjacent cells were measured.) The temperature of adjacent cells was $43^{\circ} \mathrm{C}$ and $47^{\circ} \mathrm{C}$ at $219 \mathrm{~s}$ (when laser irradiation was stopped). The temperatures reached highs of $126^{\circ} \mathrm{C}$ and $136^{\circ} \mathrm{C}$, then gradually decreased.

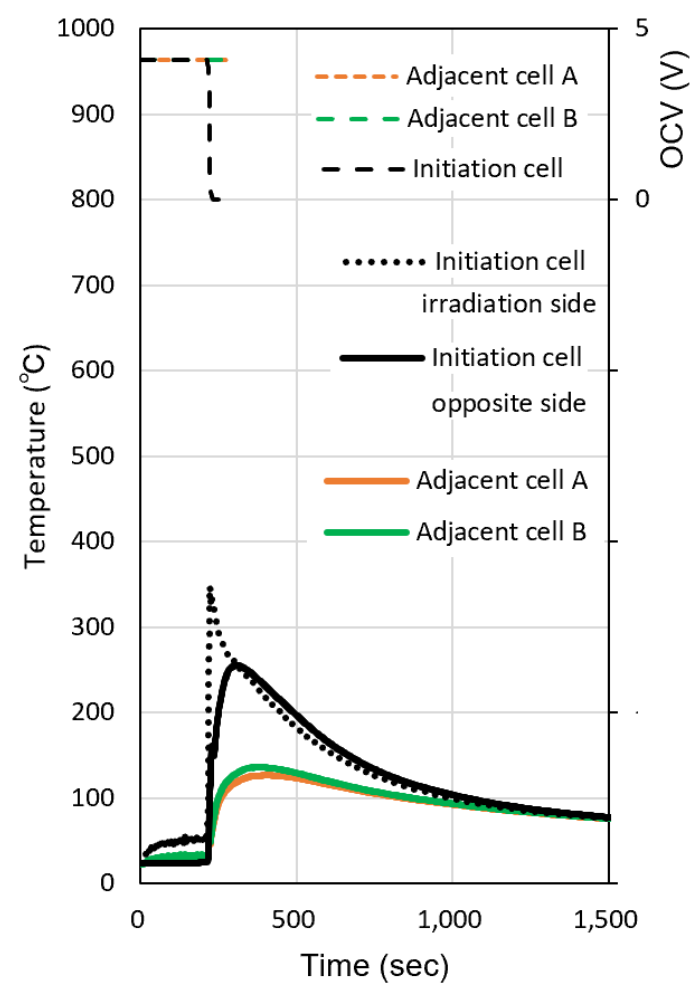

Fig. 5 Temperature and OCV profile for pack test

After opening the plastic cover, no venting from adjacent cells was confirmed.

(iv) Judgment of pass/fail for thermal propagation of pack level test

The battery pack was judged to have passed the thermal propagation test against our criterion of "No fire or explosion, and no smoke originating from adjacent cells outside of the plastic covering the battery pack within 5 minutes after a thermal event". The first thermal event of venting on the initiation cell was confirmed at $235 \mathrm{~s}$ after laser irradiation. Therefore, the "5 minutes after a thermal event" corresponded to $535 \mathrm{~s}$ after laser irradiation. In this experiment, no thermal event originating from adjacent cells was observed up to $535 \mathrm{~s}$ after laser irradiation.

(v) Confirmation of maintaining the advantage

One of the advantages of causing thermal runaway with minimal heating of adjacent cells was confirmed to be maintained in the case of the pack level test because the increase in temperature of adjacent cells was so small (Fig. 5). The rapid increase of initiation cell temperature (irradiation side) after 215 $\mathrm{s}$ was caused by adding internal heat from the cell to the external heat from the laser. Therefore, the time frame during 0-215 s was selected to focus on the external heat from the laser, excluding internal heat from the cell. The initiation cell temperature (irradiation side) increased from $23^{\circ} \mathrm{C}$ to $69^{\circ} \mathrm{C}$, that of adjacent cell A increased from $23^{\circ} \mathrm{C}$ to $30^{\circ} \mathrm{C}$, and that of adjacent cell $\mathrm{B}$ increased from $23^{\circ} \mathrm{C}$ to $31^{\circ} \mathrm{C}$. The temperature increase of adjacent cells was less than that of the initiation cell. The laser irradiation was stopped at $219 \mathrm{~s}$. Therefore, the time frame during $0-215 \mathrm{~s}$ was extended to during $0-219 \mathrm{~s}$ to evaluate the influence of total energy input by laser irradiation. The initiation cell temperature (irradiation side) was $256^{\circ} \mathrm{C}$ at $219 \mathrm{~s}$. The temperatures of adjacent cell $\mathrm{A}$ and $\mathrm{B}$ were $43^{\circ} \mathrm{C}$ and $47^{\circ} \mathrm{C}$, 
Vol.13, No.1(2022)

respectively. The temperature increase of $24^{\circ} \mathrm{C}\left(=47^{\circ} \mathrm{C}-23^{\circ} \mathrm{C}\right)$ for adjacent cell $\mathrm{B}$ was approx. $10 \%$ of the temperature increase of $233^{\circ} \mathrm{C}\left(=256-23^{\circ} \mathrm{C}\right)$ for the initiation cell at $219 \mathrm{~s}$.

\subsection{Summary of thermal propagation tests Results}

Thermal propagation tests for a battery module and pack in PHEVs were conducted, and demonstrated the practicality of using laser irradiation as an initiation method. The success criterion and the pass/fail criterion were set as examples for evaluating the results. The use of laser irradiation for heating has an advantage of causing thermal runaway with minimal heating of adjacent cells. The results revealed that the advantage of laser irradiation is maintained at the pack level test for vehicles.

\section{Conclusion}

We studied the mechanism of laser irradiation for heating the initiation cell and its features. We demonstrated a practical example of the applicability of laser irradiation for thermal propagation tests with a battery pack in PHEVs. One of the advantages of causing thermal runaway with minimal heating of adjacent cells was confirmed to be maintained in the case of the pack level test.

"This paper is written based on a proceeding presented at JSAE 2021 Annual Congress"

\section{References}

(1) W.Walker, "Fundamentals, thermal performance and understanding thermal runaway", Short course on lithium-ion batteries, NASA Thermal fluids and analysis workshop 2015, p23, 2015.

(2) A. Kriston, A. Kersys, A. Antonelli, S. Ripplinge, S. Holmstrom, S. Trischler, H. D€oring, A. Pfrang, "Initiation of thermal runaway in Lithium-ion cells by inductive heating", Journal of Power Sources Volume 454, 227914, 2020.

(3) J. Diekmannz, S. Doose, S. Weber, S. Münch, W. Haselrieder, and A. Kwade, "Development of a New Procedure for Nail Penetration of Lithium-Ion Cells to Obtain Meaningful and Reproducible Results", Journal of The Electrochemical Society, Volume 167, 090504, 2020.

(4) Shironita, S., Tsuruga, H., Honda, K., Koshika, K., Umeda, M., "Thermal runaway characteristics of a LiFePO4-based lithium-ion secondary battery using the laser-irradiation method" Journal of Energy Storage, Volume 40, 102715 , 2021.

\section{(5) IEC62619}

"Secondary cells and batteries containing alkaline or other nonacid electrolytes - Safety requirements for secondary lithium cells and batteries, for use in industrial applications", International electrotechnical commission (IEC), 2017.

(6) "Japan research of thermal propagation test", 15th EVS-IWG, 2018.

(https://wiki.unece.org/display/trans/EVS+15th+session)

(7) "Japan research of thermal propagation test", 16th EVS-IWG, 2018.

(https://wiki.unece.org/display/trans/EVS+16th+session)

(8) J. Svenungsson, I. Choquet, A. Kaplan, "Laser Welding Process - A Review of Keyhole Welding Modelling", Physics Procedia, Volume 78, 182-191, 2015.

(9) L. Wang, M. Mohammadpour, B. Yang, X. Gao, J. Lavoie, K. Kleine, F. Kong, and R. Kovacevic, "Monitoring of keyhole entrance and molten pool with quality analysis during adjustable ring mode laser welding", Applied Optics, Volume 59, Issue 6, 1576-1584, 2020.

(10) Global Technical Regulation No. 20 (Electric Vehicle Safety), https://unece.org/transport/standards/transport/vehicleregulations-wp29/global-technical-regulations-gtrs 